\title{
Lack of consensus on corneal abrasion management: results of a national survey
}

\author{
Lisa Calder, MD; Sowmya Balasubramanian, MSc; Ian Stiell, MD, MSc
}

\begin{abstract}
Objectives: Our objective was to determine the practice patterns of Canadian emergency physicians with respect to the management of traumatic corneal abrasions.

Methods: After developing our instrument and pilot testing it on a sample of emergency residents, we randomly surveyed $\mathbf{4 7 0}$ members of the Canadian Association of Emergency Physicians, using a modified Dillman technique. We distributed a pre-notification letter, an 18-item survey, and appropriate follow-up surveys to non-responders. Those members with an email address ( $n=$ 400) received a Web-based survey, and those without $(n=70)$ received a survey by post. The survey focused on the indications and utilization of analgesics (oral and topical), cycloplegics, eye patches and topical antibiotics.

Results: Our response rate was $64 \%$ (301/470), and the median age of respondents was 38 years. Most $(77.7 \%)$ were male, $71.8 \%$ were full-time emergency physicians, $76.5 \%$ were emergency medicine certified, and $64.4 \%$ practised in teaching hospitals. Pain management preferences (offered usually or always) included oral analgesics $(82.1 \%)$, cycloplegics $(65.1 \%)$ and topical nonsteroidal anti-inflammatory drugs (NSAIDs) $(52.8 \%)$. Only $21.6 \%$ of respondents performed patching, and most $(71.2 \%)$ prescribed topical antibiotics, particularly for contact lens wearers and patients with ocular foreign bodies. Two-thirds of the respondents provided tetanus toxoid if a foreign body was present, and $46.2 \%$ did so even if a foreign body was not present. Most respondents (88.0\%) routinely arranged follow-up.

Conclusions: This national survey of emergency physicians demonstrates a lack of consensus on the management of traumatic corneal abrasions. Further study is indicated to determine the optimal treatment, particularly regarding the use of topical NSAIDs.
\end{abstract}

Key words: corneal abrasion; survey; emergency medicine

\begin{abstract}
RÉSUMÉ
Objectifs : Notre objectif était de déterminer les habitudes de pratique des médecins d'urgence quant à la prise en charge des abrasions cornéennes traumatiques.

Méthodes : Après avoir créé notre instrument et en avoir fait l'essai auprès d'un échantillon de médecins d'urgence, nous avons fait un sondage au hasard auprès de 470 membres de l'Association canadienne des médecins d'urgence à l'aide d'une technique Dillman modifiée. Nous avons distribué une lettre de préavis, un sondage en 18 points et des sondages de suivi appropriés à ceux qui n'ont pas répondu. Les membres ayant une adresse de courrier électronique $(n=400)$ reçurent un sondage sur le Web et ceux qui n'en avaient pas $(n=70)$ reçurent un sondage par la poste. Le sondage portait sur l'indication et l'utilisation des analgésiques (oraux et topiques), les
\end{abstract}

From the Department of Emergency Medicine, University of Ottawa, Ottawa, Ont.

Received: Feb. 12, 2004; final submission: July 10, 2004; accepted: July 15, 2004

This article has been peer reviewed.

Can J Emerg Med 2004;6(6):402-7 
cyclopégiques, les pansements oculaires et les antibiotiques topiques.

Résultats : Le taux de réponse fut de 64\% (301/470) et l'âge moyen des répondants était de 38 ans. La plupart d'entre eux étaient des hommes $(77,7 \%), 71,8 \%$ étaient médecins d'urgence à plein temps, $76,5 \%$ étaient certifiés en médecine d'urgence et $64,4 \%$ travaillaient dans des hôpitaux universitaires. Les préférences de prise en charge de la douleur (offerte la plupart du temps ou toujours) incluaient les analgésiques oraux $(82,1 \%)$, les cyclopégiques $(65,1 \%)$ et les anti-inflammatoires non stéroïdiens (AINS) $(52,8 \%)$. Seulement $21,6 \%$ des répondants avaient recours aux pansements et la plupart (71,2 \%) prescrivaient des antibiotiques topiques, surtout pour les patients portant des lentilles cornéennes et pour ceux qui avaient un corps étranger dans l'œil. Les deux tiers des répondants offraient un toxoïde tétanique si un corps étranger oculaire était en cause et $46,2 \%$ l'offraient même en l'absence d'un corps étranger. La plupart des répondants $(88,0 \%)$ organisaient un suivi de façon routinière.

Conclusions : Ce sondage à l'échelle nationale auprès des médecins d'urgence démontre l'absence de consensus quant à la prise en charge des abrasions cornéennes. Des études plus poussées s'imposent afin de déterminer le traitement optimal, surtout en ce qui concerne le recours aux AINS topiques.

\section{Introduction}

Traumatic corneal abrasions are common in Canadian emergency departments (EDs), with an estimated 20000 cases per year in the province of Quebec alone. ${ }^{1}$ Possible treatment modalities include analgesics (oral and topical), cycloplegics, topical non-steroidal anti-inflammatory drugs (NSAIDs), eye patches and topical antibiotics, although there is a paucity of evidence supporting any of these modalities. Several randomized trials show promising results for the use of topical NSAIDs, ${ }^{2-8}$ but cost is a concern. Eight randomized trials ${ }^{1,9-15}$ and one meta-analysis ${ }^{16}$ conclude that patching is not routinely indicated. There are no studies showing that topical antibiotics are of value, and 1 clinical trial demonstrated that topical antibiotics are of no benefit in low-risk corneal abrasions. ${ }^{17}$ The only randomized controlled trial examining the use of cycloplegics suggested they do not improve pain scores or reduce oral analgesic requirements. ${ }^{18}$ Yet, despite a lack of evidence, topical antibiotics and cycloplegics remain recommended treatments in emergency medicine textbooks. ${ }^{19,20}$

British investigators have documented substantial variability in corneal abrasion management among ophthalmology clinics. ${ }^{21}$ It is not known whether similar variability exists in Canadian EDs. Our objective was to characterize the corneal abrasion management practices of Canadian emergency physicians. Our hypothesis was that we would find a significant lack of consensus and establish the need for future randomized controlled trials defining optimal therapy.

\section{Methods}

\section{Survey development}

We designed a national survey using a modified Dillman technique..$^{22}$ The 18 survey questions -11 multiple choice and 7 "fill in the blank" with numerical responses - were based upon previous research ${ }^{21-24}$ and focused on 4 main therapeutic modalities: analgesics (oral and topical), cycloplegics, eye patches and topical antibiotics. Topical anesthetics were not addressed because these are not prescribed for outpatient use. The survey also assessed slit-lamp use, tetanus immunization and follow-up arrangements. We elicited demographic information, characteristics of practice setting and training background. The full questionnaire is available from the corresponding author (L.C.).

\section{Pilot testing}

A pilot survey was mailed electronically to all emergency medicine residents at the University of Ottawa and the University of British Columbia. Each resident received an additional questionnaire concerning the clarity, content and overall formatting of the survey. There was a $95 \%$ response rate to the pilot survey. All respondents found the questions to be clear, and none suggested areas of missing content.

\section{Study subjects}

We randomly selected 400 members of the Canadian Association of Emergency Physicians (CAEP) using a computer-generated random number scheme. Of these, 72 (18\%) did not have email addresses; these members were then re-entered into the pool. To avoid selection bias, we sent questionnaires to a random sample of 70 members by post. Our overall sample of 470 subjects represented 35\% of CAEP's total membership (1388) in June of 2002. Respondents were informed their anonymity would be preserved and that their response implied consent. The study was approved by the Ottawa Hospital Research Ethics Board. 


\section{Web-based survey}

The survey was converted into HTML (hypertext markup language) format by a Web-page designer. The Web format was pre-tested by the investigators and the Ottawa Health Research Institute (OHRI) Web site staff. Four hundred emergency physicians were emailed a cover letter containing a link to the survey, which was on the OHRI Web site. The email included a password in order to protect the respondent's identity.

Non-respondents received a reminder email after 4 weeks. Non-respondents were then re-emailed a third time 6 weeks after launch and again 4 weeks later. Those who had technical difficulties with the Web survey were sent postal questionnaires. Potential respondents who had invalid email addresses were replaced by additional subjects randomly selected from the CAEP membership database.

\section{Postal questionnaire}

Those who were sent a postal questionnaire received an introductory letter and self-addressed stamped envelope with each survey. We did not provide French language surveys and asked respondents to return an empty envelope if they did not complete the questionnaire for this reason. Each survey was assigned a random identification number in order to protect the respondent's identity. Reminder cards were mailed 4 weeks after the first mailing, and a second survey was sent to non-responders 2 weeks after the reminder card. Potential respondents with invalid addresses were replaced by additional subjects randomly selected from the CAEP membership.

\section{Data analysis}

Data were entered into a Microsoft Access database, and descriptive statistics, including means, medians, proportions and $95 \%$ confidence intervals (CIs), were calculated using SAS (version 8, Cary, NC).

\section{Results}

Figure 1 shows that we had 301 survey respondents, for a response rate of $64.0 \%$, which is comparable to the $61 \%$ average response rate reported in the literature for physician surveys. ${ }^{25}$ No envelopes were returned because of language issues, but 46 email addresses were invalid and 29 respondents had irresolvable problems using the Web survey. These respondents received postal questionnaires.

Demographic data are summarized in Table 1. Of 301 respondents, 292 (97.0\%) have slit lamps in their ED and $93.8 \%$ use the slit lamp. Figure 2 shows that 247 subjects $(82.1 \%)$ usually or always prescribe oral analgesics, 196
(65.1\%) prescribe cycloplegics and $159(52.8 \%)$ prescribe topical NSAIDs. Of those who never prescribe NSAIDs, $11.3 \%$ are unconvinced of their efficacy and $9.6 \%$ consider them too expensive.

Overall, $71.2 \%$ of respondents (95\% CI, 66\%-76\%) prescribe oral antibiotics. Table 2 shows that oral antibiotics are most likely prescribed for contact lens wearers, patients with corneal foreign bodies, and fingernail-induced injuries. $46.2 \%$ of respondents routinely update tetanus immunization even if there is no foreign body present, and $64.8 \%$ do so only when there is a foreign body. Even fewer respondents (21.6\%; 95\% CI, 17\%-26\%) use eye patches. In this group, reported indications for patching included largesized abrasions (38.2\%), photophobia (30.9\%) and severe pain $(29.9 \%)$. The mean recommended duration of patching is 20.7 hours.

A majority of physicians (88.0\%) arrange routine followup. This most often involves advice to return to the ED for re-check (69.4\% of respondents), but $45.2 \%$ refer the patient to an ophthalmologist and $35.2 \%$ refer to the family physician. Two-thirds of respondents reported that ophthalmologists are "usually" or "always" available for follow-up.

\section{Discussion}

This is the first published survey assessing emergency physician management of traumatic corneal abrasions. It demonstrates substantial variability and a lack of consensus with respect to the ED treatment of these injuries. Our data suggest that oral analgesics are the therapeutic modality most often used, followed by topical antibiotics and cycloplegics. We found that emergency physicians rarely perform patching, but use a variety of management strategies despite

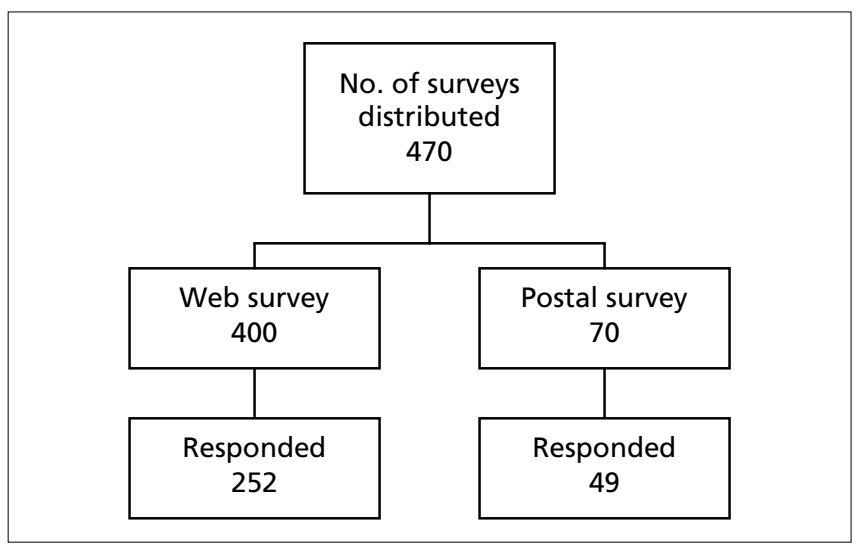

Fig. 1. Survey flow. Of the 169 non-respondents, 29 did not respond because of unresolvable technical problems, 10 were not emergency physicians, 2 surveys were lost due to "incorrect address" and for 128, the reason for non-response was unknown. 
a body of literature that supports minimal intervention.

A literature search revealed only one prior survey of clinical practice, and this involved 134 ophthalmology units in the United Kingdom. ${ }^{21}$ In this study, Sabri and colleagues $^{21}$ reported that topical antibiotics and cycloplegics were the most commonly prescribed treatments (despite a lack of supporting evidence) and that a minority of respondents performed patching. Our results are consistent with these findings, as Sabri and colleagues did not ask about oral analgesics or topical NSAIDs.

\section{Therapeutic agents}

Cycloplegics paralyze the ciliary muscle to prevent painful

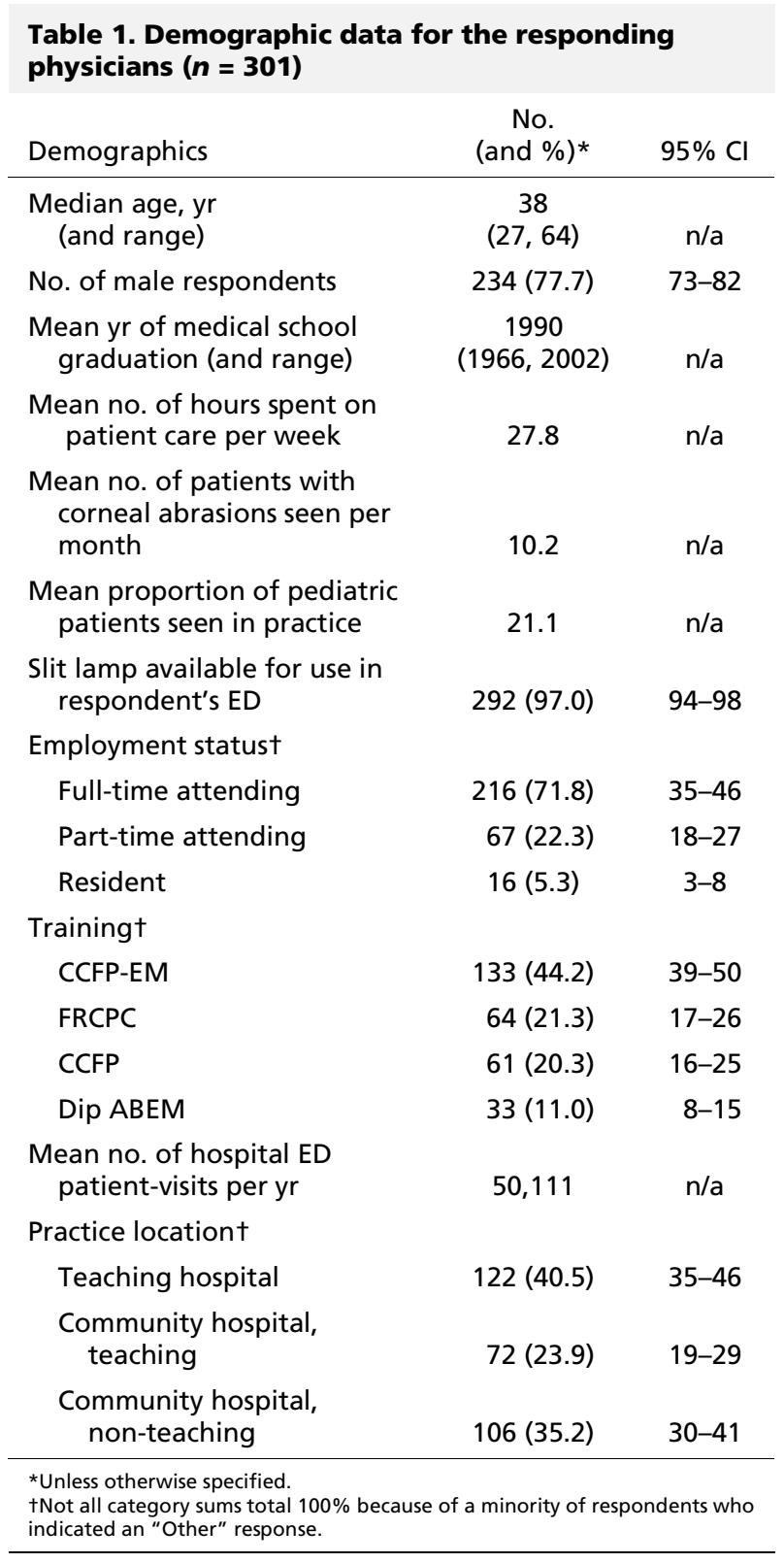

pupillary spasm in patients with traumatic corneal abrasions. In our study, $65.1 \%$ of respondents expressed the opinion that these agents are effective. While their use may seem physiologically intuitive, it has not been well studied. We found only 1 randomized controlled trial ${ }^{18}$ looking at the use of cycloplegics for traumatic corneal abrasions. This study of lubrication, cycloplegics and topical flurbiprofen concluded that topical homatropine did not improve visual analog pain scores during the first 24 hours, but that topical NSAID therapy did. The study was limited by a $50 \%$ loss to follow-up but it suggests a limited role for cycloplegics.

Topical NSAIDs have emerged as an alternative anal-

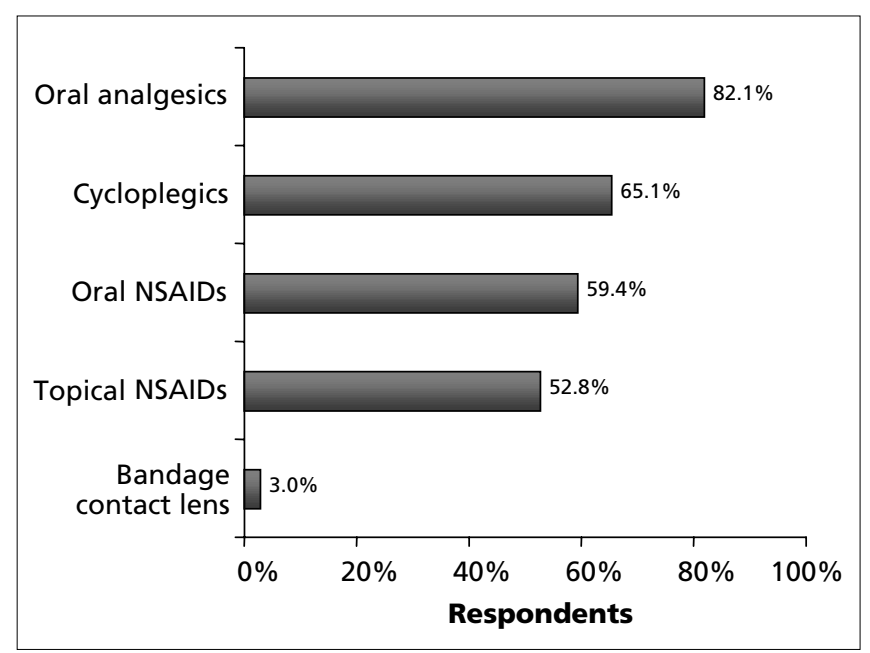

Fig. 2. Choice of analgesics among respondents. NSAIDs = non-steroidal anti-inflammatory drugs.

Table 2. Indications and first choice of topical antibiotic for responding physicians $(n=301)$

\begin{tabular}{lcc} 
Variable & $\begin{array}{c}\text { No. } \\
(\text { and \%)* }\end{array}$ & $\begin{array}{c}95 \% \\
\mathrm{Cl}\end{array}$ \\
\hline $\begin{array}{l}\text { Indications for topical antibiotics } \\
\text { Contact lens wearer }\end{array}$ & $223(74.1)$ & $69-79$ \\
Foreign body presence & $214(71.1)$ & $66-76$ \\
Fingernail-induced abrasion & $206(68.4)$ & $63-73$ \\
Only if signs of infection present & $10(3.3)$ & $2-6$ \\
Topical antibiotic of first choice & & \\
Sodium sulfacetamide & $110(36.5)$ & $31-42$ \\
Bacitracin/polymyxin B & $39(13.0)$ & $9-17$ \\
Erythromycin & $38(12.6)$ & $9-17$ \\
Gentamicin & $33(11.0)$ & $8-15$ \\
Ciprofloxacin & $22(7.3)$ & $5-11$ \\
Chloramphenicol & $7(2.3)$ & $1-5$ \\
Other & $5(1.7)$ & $1-4$ \\
\hline
\end{tabular}


gesic for traumatic corneal abrasions. Six of 7 randomized controlled trials ${ }^{3-8,18}$ reported significant reductions in pain scores with NSAID use. The 7th found no significant difference in pain relative to placebo, but did document lower oral opioid requirements in the NSAID group. ${ }^{7}$ Four tri$\mathrm{als}^{3,4,6,7}$ measured abrasion healing times and found no significant differences with NSAID use. Although there is ample evidence to support the analgesic effectiveness of this modality, we found a lack of consensus on its use among our survey respondents.

Eight randomized controlled trials have shown that patching is not effective for corneal abrasions. ${ }^{1,9-15}$ The majority of these studies reported no difference in levels of discomfort, and most also found that patches were associated with slower healing. A meta-analysis of 7 randomized controlled trials ${ }^{16}$ supported these conclusions. Only $21.6 \%$ of our respondents perform patching, indicating that the evidence has likely impacted upon physicians' practice.

Ophthalmologists sometimes recommend bandage contact lens for comfort following surgical procedures. This modality has not been picked up by the emergency medicine community, and only 9 of our respondents (3.0\%) reported using bandage contact lenses, perhaps because of the need for close ophthalmology follow-up.

There are few studies in the literature examining the use of prophylactic topical antibiotics in traumatic corneal abrasions. Kruger and associates ${ }^{26}$ conducted a randomized controlled trial comparing antibiotic to placebo in 94 patients with corneal foreign bodies; it showed no difference in pain or healing time. Unfortunately, this small study did not examine infection as an outcome. In a Canadian prospective cohort study, King and Brison ${ }^{17}$ followed 270 patients with traumatic corneal abrasions, $64 \%$ of these cases were complicated by foreign bodies. None received topical antibiotics, and the documented infection rate, with $90 \%$ follow-up, was $0.7 \%$. They concluded that prophylactic topical antibiotics are not indicated for traumatic corneal abrasions. The exception to this conclusion would be contact lens wearers who are more prone to Pseudomonas infected corneal ulcers. ${ }^{27}$ Given the documented rarity of infection, it was surprising that most of our survey respondents prescribed topical antibiotics routinely for corneal abrasions.

Case reports of tetanus infection following penetrating eye injury suggest that tetanus immunization may be of value in such cases..$^{28-30}$ Using a mouse model, Benson and colleagues $^{31}$ found that Clostridium tetani could not colonize the eye unless the cornea was perforated, and attributed this to the avascular nature of the cornea. British practice guidelines ${ }^{32}$ and other authors ${ }^{33}$ have since recommended using tetanus prophylaxis only for penetrating eye trauma and not for simple corneal abrasions. Among our respondents, $46.2 \%$ routinely update tetanus immunization even if there is no foreign body present, and $64.8 \%$ do so only when there is a foreign body. This lack of consensus suggests uncertainty about the risk of tetanus infection after corneal injury.

\section{Study limitations}

In survey research, self-selection bias is always a concern and survey respondents may be different from non-respondents. Because CAEP does not collect demographic data, we cannot determine whether our sample is representative of all emergency physicians. In particular, our data may not reflect physicians who work in rural EDs. In addition, it is likely there is some element of social desirability bias, whereby respondents answer according to what they believe the right answer is rather than their actual practice. We hope that survey anonymity minimized this effect.

There were technical difficulties with our Web survey on the first 2 days, which resulted in 80 lost responses. Fortunately, $65 \%$ of these respondents re-entered their responses. Five of 9 studies comparing email to postal surveys found no difference or improved response rates with email surveys. ${ }^{34}$ These authors also suggested that lack of familiarity with technology can adversely affect response rate, and we did note variability in the respondents' technical capabilities across the country. The strengths of our survey lie in its large sample size, the Web-based format, which allows for a shorter response time while preserving anonymity, and the fact that we assessed content validity in a pilot phase.

\section{Conclusions}

There is a lack of consensus among Canadian emergency physicians regarding the management of traumatic corneal abrasions. Antibiotics and cycloplegics are widely used despite a lack of supporting evidence, and topical NSAIDs and tetanus immunization are variably used. This lack of consensus reflects the paucity of high quality evidence and suggests the need for further study to determine optimal ED management, particularly with respect to the use of NSAIDs.

Competing interests: None declared.

Acknowledgements: Thank you to several people who assisted with this project: Jennifer Cookman and Jessica Hacker for Web design; My-Linh Tran for statistical analysis; Sheryl Domingo for data entry; Mike Hendley for Web page management and Christine Merrikin for her assistance in collating the postal survey. Thank 
you also to Drs. Christian Vaillancourt and Jeff Perry for their suggestions in revising the manuscript.

Supported by a grant from the Canadian Association of Emergency Physicians.

\section{References}

1. Le Sage N, Verreault R, Rochette L. Efficacy of eye patching for traumatic corneal abrasions: a controlled clinical trial. Ann Emerg Med 2001;38(2):129-34.

2. Eke T, Morrison DA, Austin DJ. Recurrent symptoms following traumatic corneal abrasion: prevalence, severity, and the effect of a simple regimen of prophylaxis. Eye 1999;13(Pt 3a):345-7.

3. Kaiser PK, Pineda IR, An B, Brun S, Burk S, Kim R, et al. A study of topical nonsteroidal anti-inflammatory drops and no pressure patching in the treatment of corneal abrasions. Ophthalmology 1997;104(8):1353-9.

4. Patrone G, Sacca SC, Macri A, Rolando M. Evaluation of the analgesic effect of $0.1 \%$ indomethacin solution on corneal abrasions. Ophthalmologica 1999;213(6):350-4.

5. Jayamanne DGR, Fitt AWD, Andrews RM, Mitchell KW, Griffiths PG. The effectiveness of topical diclofenac in relieving discomfort following traumatic corneal abrasions. Eye 1997;11:79-83.

6. Alberti MM, Bouat CG, Allaire CM, Trinquand CJ; and the study group. Combined indomethacin/gentamicin eyedrops to reduce pain after traumatic corneal abrasion. Eur J Ophthalmol 2001;11:233-9.

7. Goyal R, Shankar J, Fone DL, Hughes DS. Randomised controlled trial of ketorolac in the management of corneal abrasions. Acta Ophthalmol Scand 2001;79:177-9.

8. Szucs PA, Nashed AH, Allegra JR, Eskin B. Safety and efficacy of diclofenac ophthalmic solution in the treatment of corneal abrasions. Ann Emerg Med 2000;35(2):131-7.

9. Hulbert MFG. Efficacy of eyepad in corneal healing after corneal foreign body removal. Lancet 1991;337:643.

10. Kirkpatrick JNP, Hoh HB, Cook SD. No eye pad for corneal abrasion. Eye 1993;7:468-71.

11. Patterson J, Fetzer D, Krall J, Wright E, Heller M. Eye patch treatment for the pain of corneal abrasion. South Med J 1996;89(2):227-9.

12. Kaiser PK; the Corneal Abrasion Patching Study Group. A comparison of pressure patching versus no patching for corneal abrasions due to trauma or foreign body removal. Ophthalmology 1995;102:1936-42.

13. Campanile TM, St. Clair DA, Benaim M. The evaluation of eye patching in the treatment of traumatic corneal epithelial defects. J Emerg Med 1997;15(6):769-74.

14. Arbour JD, Brunette I, Boisjoly HM, Shi ZH, Dumas J, Guertin C. Should we patch corneal erosions? Arch Ophthalmol 1997;115:313-7.

15. Michael JG, Hug D, Dowd MD. Management of corneal abrasion in children: a randomized clinical trial. Ann Emerg Med 2002;40:67-72.

16. Flynn CA, D'Amico F, Smith G. Should we patch corneal abrasions? A meta-analysis. J Fam Pract 1998;47:264-70.

17. King JWR, Brison RJ. Do topical antibiotics help corneal epithelial trauma? Can Fam Physician 1993;39:2349-52.
18. Brahma AK, Shah S, Hillier VF, McLeod D, Sabala T, Brown A, et al. Topical analgesia for superficial corneal injuries. J Accid Emerg Med 1996;13(3):186-8.

19. Tintanalli JE, Kelen GD, Stapczynski JS. Emergency medicine: a comprehensive study guide. 5th ed. New York: McGraw-Hill Companies Inc; 2000.

20. Marx JA, Hockberger RS, Walls RM. Rosen's emergency medicine: concepts and clinical practice. 5 th ed. St. Louis (MO): Mosby Inc.; 2002.

21. Sabri K, Pandit JC, Thaller VT, Evans NM, Crocker GR. National survey of corneal abrasion treatment. Eye 1998;12(Pt 2):278-81.

22. Dillman DA. Mail and telephone surveys: the total design method. Washington: John Wiley and Sons Inc; 1978.

23. Graham ID, Stiell IG, Laupacis A, McAuley L, Howell M, Clancy $\mathrm{M}$, et al. Awareness and use of the Ottawa ankle and knee rules in 5 countries: Can publication alone be enough to change practice? Ann Emerg Med 2001;37(3):259-66.

24. Hebert PC, Wells G, Martin C, Tweeddale M, Marshall J, Blajchman $\mathrm{M}$, et al. A Canadian survey of transfusion practices in critically ill patients. Crit Care Med 1998;26(3):482-7.

25. Cummings SM, Savitz LA, Konrad TR. Reported rates to mailed physician questionnaires. Health Services Research 2001;35(6):1347-55.

26. Kruger RA, Higgins J, Rashford S, Fitzgerald B, Land R. Emergency eye injuries. Aust Fam Physician 1990;19(6):934-8.

27. Morlet N, Daniell M. Empirical fluoroquinolone therapy is sufficient initial treatment. Br J Ophthalmol 2003;87:1167-9.

28. Searl SS. Minor trauma, disastrous results. Surv Ophthalmol 1987;31(5):337-42.

29. Iyer MN, Kranias G, Daun ME. Post-traumatic endophthalmitis involving Clostridium tetani and Bacillus spp. Am J Ophthalmol 2001;132(1):116-7.

30. Muddappa TM, Rao PN. Ocular tetanus. Indian J Ophthalmol 1982;30(3):163-5.

31. Benson WH, Snyder IS, Granus V, Odom VJ, Macsai MS. Tetanus prophylaxis following ocular injuries. J Emerg Med 1993;11:677-83.

32. The Sowerby Center for Informatics, Department of Health, Government PRODIGY Guidance: practical support for clinical governance. Corneal Superficial Injury. Available: www.prodigy .nhs.uk/guidance.asp?gt=corneal\%20superficial\%20injury (accessed 2004 July 15).

33. Mahadevan SV, Savitsky E, Winograd SM. Emergency management of traumatic eye injuries. Trauma Reports 2001;July:1. Available: www.emronline.com/trauma_archives.html (accessed 2004 Sept; authorization required).

34. Sheehan KB, Grubbs Hoy M. Using email to survey internet users in the United States: methodology and assessment. J Computer-Mediated Communication (JCMC) 1999;4(3):1-26. Available: www.sysurvey.com/tips/using_e-mail_to_survey.htm (accessed 2004 July 15).

Correspondence to: Dr. Lisa Calder, Department of Emergency Medicine, The Ottawa Hospital, Civic Campus, 1053 Carling Ave., Ottawa ON K1Y 4E9; 613 798-5555 x17484, lcalder@sympatico.ca 